'heightened sensitivity for liberal and democratic values'. There were even calls from some German psychiatrists for a move to community-based care, revealing an active response to the social questions of the day.

This is an exhaustively referenced work, and one that makes a significant contribution to the psychiatric history of the period. What would be fascinating would be an examination of how these trends influenced the German response to the mass psychiatric casualties of the First World War.

Hugh Freeman Honorary Visiting Fellow, Green College, Oxford OX2 6HG, UK

\section{Post-Traumatic Stress Disorder: Malady or Myth?}

By Chris R. Brewin.

New Haven, CT:Yale University Press. 2003.

272 pp. $€ 25$ (hb).

ISBN 0300099843

Chris Brewin is the Professor of Psychology at University College London and is an expert in both post-traumatic stress disorder (PTSD) and memory. This volume is from the Current Perspectives in Psychology Series.

As the title might lead one to expect, Professor Brewin initially explores the topic in an adversarial way, presenting the argument for and against the concept of

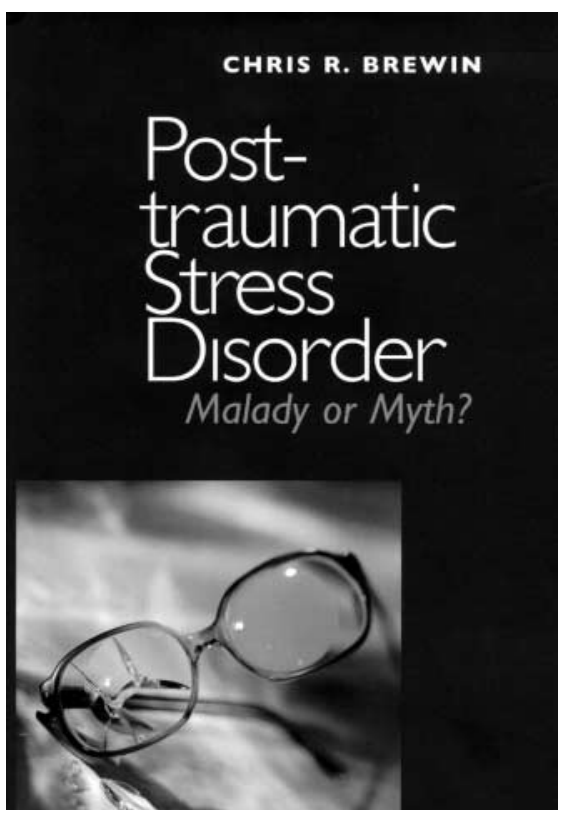

the disorder. This forms a substantial part of the book and it is not something that one could readily deduce from the title, which is a pity as there are few reviews of this subject in the PTSD literature.

The author covers a wide range of issues related to memory, including concepts of repression, the recovered memory debate and how this relates to Freudian theory. He criticises both sides of the debate for failing to distinguish between observations and theoretical explanation. He then presents some of his own research on memory inhibition and argues for the concepts of a visual accessible memory (VAM) and a situational accessible memory (SAM), which form part of the dual representation theory for PTSD. This provides a feasible explanation for the phenomena of repression and dissociation.

One chapter covers the prevention and treatment of PTSD, including the controversial area of psychological debriefing. Finally, there is a summing up and a look to the future.

Overall, this is a well-written volume with excellent and comprehensive references (although I would have preferred a title that was more indicative of the content). It would be of value both to a relative newcomer to the subject and to an expert. international rather than purely North American perspective. Less predictable, and arguably more interesting, Brewin then reviews the evidence and explores possible theories that explain the laying down of traumatic memories and how this process might shed light on the core symptoms of
Martin Baggaley Consultant Psychiatrist, South London and Maudsley NHS Trust, Ladywell Mental Health Unit, Lewisham Hospital, Lewisham High Street, London SEI3 6LW, UK 